
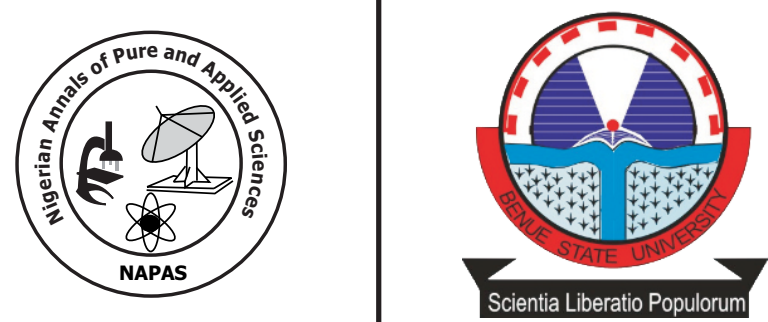

\title{
Analysis of Technical and Allocative efficiencies among Cotton Producers in Nagpur District, Maharashtra State, India
}

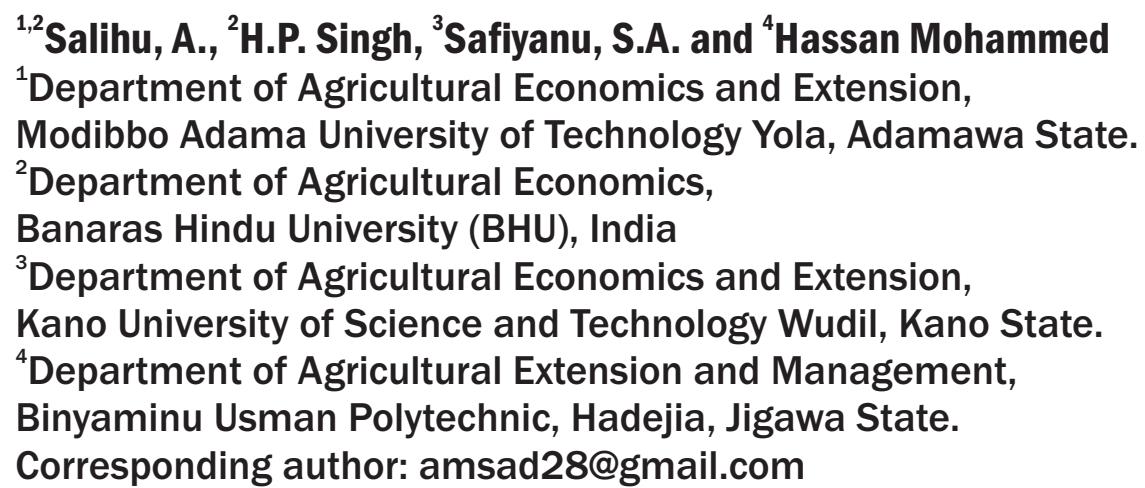

\section{Abstract}

This article assessed the technical and allocative efficiencies of cotton farmers in Nagpur district, Maharashtra, India. A multi-stage sampling technique was adopted in selecting one hundred and twenty farmers. Data were collected using structured questionnaires. Descriptive statistics, stochastic frontier production function and inefficiency model were employed for data analysis. Results from the review of socioeconomic characteristics reveal that cotton production in the study area was dominated by small and marginal farmers (96.7\%). Majority of the cotton producers $(84.2 \%)$ had small family size (2-6 persons) with low literacy rate. The results obtained from the stochastic frontier production function reveal that farm size and labour were the major determinants of cotton production in the study area. The mean technical efficiency estimate was $78 \%$, implying that farmers are highly efficient although cotton output can still be raised by $22 \%$ through better resource allocation without incurring additional cost. Estimates of Allocative efficiency indicated that agrochemical was underutilized while fertilizer and labour were over utilized. Results from the inefficiency model indicate that educational status of the farmers was the major source of inefficiency in cotton production. The study therefore suggests intensive awareness campaign and regular extension visits by concerned authorities in order to facilitate better usage of improved technology packages aimed at enhancing yield and farm income.

Key words: Efficiency, cotton production, resource use, inefficiency model 


\section{Introduction}

Cotton is an important fibre crop that belongs to the family Malvaceae and genus Gossypium. It remains an essential cash crop which is grown in tropical and subtropical areas in around 80 nations of the world. The major cotton producing countries are USA, China, India, Pakistan, Uzbekistan, Egypt, Argentina, Australia, Greece, Brazil and Turkey. Of the global cotton production, $70 \%$ comes from four countries, namely; China (27\%), India (22\%), USA (13\%) and Pakistan (USDA, 2017). For many developing and underdeveloped countries, cotton export is the main source of foreign exchange earnings.

Cotton and textiles contribute nearly one third of India's annual export, thus bringing valuable foreign exchange to the country (Manjunath, et al, 2013). Cotton cultivation in India signifies total diversity in vastness, spread, agro climate, farming methods, cropping systems, planting and marketing seasons, varieties, duration, yield, quality and costs and returns. In India, the crop occupies more than 9.2 million hectares and supports 60 million people directly and indirectly through its production, processing, marketing and trade. India's textile industry account for $7 \%$ of Gross Domestic Product, $20 \%$ of industrial output and $38 \%$ of export earnings and consists of all the three sectors - mills, power looms and handlooms (Kandidat, 2016).

The concept of efficiency is concerned with the relative performance of the processes used in transforming given inputs into outputs. Economic theory identifies at least three types of efficiency. These are technical, allocative and economic efficiencies. Allocative efficiency refers to the choice of an optimum combination of inputs consistent with the relative factor prices. Technical efficiency shows the ability of firms to employ the 'best practice' in an industry, so that no more than the necessary amount of a given sets of inputs is used in producing the best level of output. Economic efficiency is the product of technical and allocative efficiencies.

The two most popular methods of measuring efficiency, assuming the presence of inefficiency effects in the production system, are data envelopment analysis (DEA) and the stochastic frontier method. DEA is a non-parametric method, while the stochastic frontier method is parametric. Coelli (1995) compared the two methods and concluded that the main strengths of the stochastic frontier approach are its ability to deal with stochastic noise and the incorporation of statistical hypothesis tests pertaining to production structure and the degree of inefficiency.

Notable problems of cotton production in Maharashtra, India includes rising cost of inputs such as seeds, fertilizer, labour etc. Also, the minimum support price (5600 rupees per quintal) offered to cotton is far below the one required to optimally cover the high input costs (Geetha and Mahesh 2019). The productivity of cotton $(1,175 \mathrm{~kg} / \mathrm{ha})$ among farmers in India is still low compared to world's average of $2,000 \mathrm{~kg} / \mathrm{ha}$ in USA and $1,816 \mathrm{~kg} / \mathrm{ha}$ in Egypt. Thus, improving the efficiency of resource allocation will lead to higher yield and consequently more farm income. Hence, this paper examined the socioeconomic status of cotton farmers, estimated the levels of technical and allocative efficiencies and identified the sources of inefficiency in cotton production.

\section{Methodology \\ Description of the Study Area}

Maharashtra, a state spanning westcentral India, is best known for its fast-paced capital, Mumbai (formerly Bombay). Maharashtra is the largest cotton producer in India. The state is divided into 36 districts and has a population of 114.2 million. This study was conducted in Nagpur district which comprises 13 blocks.

\section{Source of Data and Sampling Technique}

Primary data were used for the study which were collected through structured questionnaires administered by the researcher and well trained enumerators. A multistage sampling technique was adopted in selecting the respondents. Maharashtra is divided into thirtysix districts out of which thirteen districts are involved in cotton production; Akola, Amaravati, Aurangabad, Buldhana, Chandrapur, Dhule, Jalagon, Jalna, Nagpur, Nanded, Parbhani, Wardha and Yavatmal. In the first stage, Nagpur district was purposively selected from Maharashtra because it has the highest cotton production area. The second stage involved the random selection of two blocks (Kalmeshuwa and Savner) out of the thirteen blocks in the district. In the third stage, 
two villages were randomly selected from each block making a total of four villages. In the final stage, thirty cotton farmers were randomly selected from each village making a total of one hundred and twenty cotton producers.

\section{Method of Data Analysis}

Descriptive statistics, stochastic frontier production function and inefficiency model were used to achieve the objectives of this paper. The stochastic frontier production model is specified as follows:

$Y_{i}=f(x i ; \beta) e^{\varepsilon}$ (Implicit form)

Where,

$\mathrm{Y}=$ the quantity of the original output, which is measured in kilogram $(\mathrm{kg})$

$\mathrm{X}_{\mathrm{i}}=$ a vector of input quantities

$\beta=$ a vector of parameters and

$\varepsilon=$ error term, where $\varepsilon$ is a stochastic disturbance term consisting of two independent elements $\mu$ and v.

The explicit form of the model is specified as follows;

Ln $y_{i}=\beta_{0}+\beta_{1} \ln X_{1}+\beta_{2} \ln X_{2}+\beta_{3} \ln X_{3}+\beta_{4} \ln X_{4}+$ $\mathrm{V}_{\mathrm{i}}-\mathrm{U}_{\mathrm{i}}$

Where,

$\mathrm{Y}_{\mathrm{i}}=$ Output of cotton in kilogramme $(\mathrm{kg})$

$\mathrm{X}_{1}=$ Farm size devoted to cotton production (ha)

$\mathrm{X}_{2}=$ Amount of fertilizer used in cotton production $(\mathrm{kg})$

$\mathrm{X}_{3}=$ Quantity of agrochemical used in cotton production (litres)

$\mathrm{X}_{4}=$ Labour used in cotton production (man days)

$\mathrm{V}_{\mathrm{i}}=$ Random noise

$\mathrm{U}_{\mathrm{i}}=$ Technical inefficiency effect which is assumed to be independent of $\mathrm{V}_{\mathrm{i}}$

This study adopted the following inefficiency model:

$\mathrm{U}_{\mathrm{i}}=\sigma_{1} \mathrm{Z}_{1}+\sigma_{2} \mathrm{Z}_{2}+\sigma_{3} \mathrm{Z}_{3}+\sigma_{4} \mathrm{Z}_{4}$

Where,

$\mathrm{U}_{\mathrm{i}}=$ Technical inefficiency effects

$\mathrm{Z}_{1}=$ Farming experience (years)

$\mathrm{Z}_{2}=$ Household size (numbers)

$\mathrm{Z}_{3}=$ Age (years)

$\mathrm{Z}_{4}=$ level of education in years

The signs of the unknown scalar parameters $\left(\sigma_{1-. .} \sigma_{4}\right)$ of the inefficiency model were used to determine the sources of inefficiency in cotton production in the study area.

The coefficients of the variables $\left(\mathrm{X}_{1}\right.$ to
$\mathrm{X}_{4}{ }^{\prime}$ of the stochastic frontier production model were used in estimating the allocative efficiency of the farmers which involves computation of Marginal value product (MVP) and Marginal Factor Cost (MFC). Allocative efficiency is determined by comparing the MVP with MFC. We assume that farmers are price takers in the input market, so that the price of factor $i$ approximates MFC. Allocative efficiency of resource $(\mathrm{AE})$ is given as

$\mathrm{AE}=\mathrm{MVP} / \mathrm{MFC}$

Marginal value product is the monetary value of marginal physical product (MPP x Py). Equation (3) indicates that when;

$\mathrm{AE}=1$, resource is efficiently utilized

$\mathrm{AE}>1$, indicates under-utilization of resources

$\mathrm{AE}<1$, indicates over-utilization of resources

\section{Results and Discussion}

\section{Socioeconomic Characteristics of the Respondents}

Distribution of the respondents based on age reveals that cotton production in the study area is dominated by middle aged persons of between 21 and 46 years of age as depicted in Table 1. This shows that most of the cotton producers are within their active age and have the strength to undertake the rigorous activities of cotton farming in order to boost their productivity and generate income to meet their financial obligations (Mustapha and Salihu, 2015).

The educational status of the farmers presented in Table 1 reveals that only few (9.1\%) of the respondents' attained $12^{\text {th }}$ class and above, while $13.3 \%$ do not have any form of formal education. The findings from the study further reveal that $41.7 \%$ of the cotton producers attained only the $5^{\text {th }}$ class as their highest educational qualification. This indicated low literacy rate among the respondents. The implication of this finding is that low literacy rate is likely to limit adoption of production technologies, thus resulting to high yield gap and consequently low level of technical efficiency of the farmers. This result corroborates the findings of Shelke et al., (2016) who reported low literacy rate among Bt cotton farmers in Beed District.

On the basis of experience, majority $(55.9 \%)$ of the cotton producers had between 2 and 25 years' experience in farming while $44.1 \%$ had above 25 years farming experience. This 
implies that the farmers are moderately experienced in farming. More years of farming experience enhances farmers' ability to manage risk and take correct decisions regarding their farm.

According to Ogunbile et al (2002), household size is the total number of individuals who live within and feed in the same house. Therefore, household is made up of the farmer, his wife(s), children and any other person that lives and share food with them. The distribution of the respondents based on household size as contained in Table 1 indicates that most of the farmers $(84.2 \%)$ had between 2 and 6 persons in their households while only $1.7 \%$ had large family size (between 12-16 persons).

The respondents in the study area cultivated a total of 325.55 hectares of land out of which $214.97(66.03 \%)$ hectares were devoted to cotton production. The findings from this study also reveal that majority $(96.7 \%)$ of the cotton producers are small and marginal farmers while the remaining are medium scale farmers. This implies that most of the respondents are small-scale farmers.

Table 1: Distribution of farmers based on their socio-economic characteristics $(n=120)$

\begin{tabular}{|c|c|c|}
\hline Variables & Frequency & Percentage \\
\hline \multicolumn{3}{|l|}{ Age } \\
\hline $21-33$ & 22 & 18.3 \\
\hline $34-46$ & 44 & 36.7 \\
\hline $47-59$ & 29 & 24.2 \\
\hline Above 59 & 25 & 20.8 \\
\hline \multicolumn{3}{|l|}{ Mean $=45.46$} \\
\hline \multicolumn{3}{|l|}{ Educational level } \\
\hline No formal education & 16 & 13.3 \\
\hline Up to $5^{\text {th }}$ class & 50 & 41.7 \\
\hline $10^{\text {th }}$ class & 43 & 35.8 \\
\hline $12^{\text {th }}$ class & 01 & 0.8 \\
\hline Tertiary & 10 & 8.3 \\
\hline \multicolumn{3}{|l|}{ Farming Experience (yrs) } \\
\hline $2-13$ & 20 & 16.7 \\
\hline $14-25$ & 47 & 39.2 \\
\hline $26-37$ & 28 & 23.3 \\
\hline $38-49$ & 25 & 20.8 \\
\hline \multicolumn{3}{|l|}{ Mean $=25.26$} \\
\hline \multicolumn{3}{|l|}{ House hold size (numbers) } \\
\hline $2-6$ & 101 & 84.2 \\
\hline $7-11$ & 17 & 14.2 \\
\hline $12-16$ & 02 & 1.7 \\
\hline \multicolumn{3}{|l|}{ Mean $=5.19$} \\
\hline \multicolumn{3}{|l|}{ Farm size (ha) } \\
\hline Marginal farmers (up to 1 ha) & 62 & 51.7 \\
\hline Small farmers $(1.01-2 \mathrm{ha})$ & 54 & 45.0 \\
\hline Medium farmers (2.01 -4ha) & 04 & 3.3 \\
\hline Total & 120 & 100 \\
\hline
\end{tabular}

Source: Field Survey, 2018

\section{Stochastic Frontier Analysis}

The estimates of the parameters of the stochastic frontier production function of the respondents are presented in Table 2. The maximum likelihood estimates of the parameters were adopted for this research work because it assumes the presence of inefficiency effects and the researcher is interested in determining the sources of inefficiency in cotton production. It is clear from the result that all the coefficients of the physical variables in the model have expected a prior signs except labour $\left(\mathrm{X}_{4}\right)$. The model reveals that the estimated coefficients of farm size $\left(\mathrm{X}_{1}\right)$, fertilizer $\left(\mathrm{X}_{2}\right)$ and quantity of agrochemicals $\left(\mathrm{X}_{3}\right)$ in the stochastic frontier production function were positive 
except labour which has a negative sign. This implies that as each of these variables $\left(\mathrm{X}_{1}, \mathrm{X}_{2}\right.$, and $\mathrm{X}_{3}$ ) are increased, cotton output will also increase. On the contrary an increase in amount of labour utilized will lead to a decrease in cotton yield, this is inconsistent with priori expectation. Farm size, and labour used were found to be statistically significant. However, quantity of fertilizer used though positively related to output was not significant. Farm size has the highest coefficient with a value of 1.0525 and by implication the farm size used existed as the most important input that impact on cotton output of the farmers. This is similar to the findings of Muhammad et al. (2011) who reported that farm size has the highest contribution to Bt cotton production in Punjab, Pakistan.

The result of the inefficiency model in Table 2 shows that the coefficients for age and household size were not statistically significant. This implies that these characteristics do not contribute to technical inefficiency. Since these variables were not significant, they do not deserve further discussion. The coefficient for farming experience and educational status are statistically significant at $10 \%$ and $1 \%$ level of probability respectively. The variables of the inefficiency model are explained in the opposite way. The negative sign of farming experience implies that the variable increase technical efficiencies of the cotton farmers. This may be due to good managerial skills that they have learnt over time. On the other hand, the positive sign of educational status in the inefficiency model shows that education increases the technical inefficiency and therefore decrease technical efficiency of the farmers. This is consistent with the findings of Khairo and Battese, (2005).

The result in Table 2 further reveals that the estimate of sigma squared $(0.0183)$ is statistically significant at $10 \%$ level of probability. This indicates a good fit of the model and the correctness of the specified distributional assumption of the composite error term. Gamma value of 0.7563 implies that $75.63 \%$ variation in cotton output in the study area is as a result of differences in technical efficiencies of the farmers.

Table 2: Maximum likelihood estimates of parameters of the stochastic frontier production function

\begin{tabular}{lccc}
\hline Variables & Parameters & Coefficients & t-ratios \\
\hline Constant & $\beta_{0}$ & $1.2948^{* *}$ & 2.294 \\
Farm size $\left(\mathrm{X}_{1}\right)$ & $\beta_{1}$ & $1.0525^{* *}$ & 2.059 \\
Fertilizer $\left(\mathrm{X}_{2}\right)$ & $\beta_{2}$ & $0.0673 \mathrm{NS}$ & 1.1905 \\
Agrochemicals $\left(\mathrm{X}_{3}\right)$ & $\beta_{3}$ & $0.0917 \mathrm{NS}$ & 1.776 \\
Labour $\left(\mathrm{X}_{4}\right)$ & $\beta_{4}$ & $-0.1242^{*}$ & -1.8851 \\
Inefficiency model & & & \\
Farming experience & $\delta_{1}$ & $-0.0195^{*}$ & -1.907 \\
Household size & $\delta_{2}$ & $-0.0521 \mathrm{NS}$ & -0.379 \\
Age of the farmer & $\delta_{3}$ & $-0.0493 \mathrm{NS}$ & -0.209 \\
Educational level & $\delta_{4}$ & $0.0618^{* * *}$ & 4.851 \\
Sigma squared & $\delta^{2}$ & $0.0183^{*}$ & -1.8668 \\
Gamma & $\Gamma$ & $0.7563^{* * *}$ & -3.604 \\
\hline
\end{tabular}

Source: Field survey 2018. ***Significant at 1\%,** Significant at 5\%, * Significant at 10\% and NS Not Significant

\section{Technical Efficiency Estimates}

The frequency distribution of efficiency estimates obtained from the stochastic frontier production model shows that the technical efficiency of the farmers varied between $40 \%$ $94 \%$. The mean technical efficiency of the farmers is $78 \%$. Also, most of the respondents $(58.33 \%)$ operated above efficiency level of
$80 \%$. This signifies that the respondents are highly efficient although there is still room for improvement since their output is still below the frontier level. This implies that farmers' cotton output can still be raised by $22 \%$ through improved resource allocation with no additional cost. 
Table 3: Estimates of technical efficiency of the cotton farmers

\begin{tabular}{|c|c|c|}
\hline Efficiency level & Frequency & Percentage \\
\hline $0.40-0.49$ & 7 & 5.83 \\
\hline $0.50-0.59$ & 6 & 5 \\
\hline $0.60-0.69$ & 7 & 5.83 \\
\hline $0.70-0.79$ & 30 & 25 \\
\hline $0.80-0.89$ & 52 & 43.33 \\
\hline $0.90-0.99$ & 18 & 15 \\
\hline \multicolumn{3}{|l|}{ Minimum $=0.40$} \\
\hline \multicolumn{3}{|l|}{ Maximum $=0.94$} \\
\hline Mean $=0.78$ & & \\
\hline Total & 120 & 100 \\
\hline
\end{tabular}

Source: Field survey, 2018

\section{Allocative Efficiency Estimates}

Estimates of allocative efficiency using the approach of marginal utilization of input resources employed in cotton production were $0.58,2.35$ and 0.51 respectively for fertilizer, agrochemicals and labour as presented in Table 4. This implies that none of the input resources was optimally utilized. Fertilizer and labour was over utilized while quantity of agrochemicals was under-utilized. This is similar to the findings of (Tayade and Borkar, 2016). Agrochemicals was underutilized probably because they are expensive and sometimes inadequate at the time farmers need them. Labour was over utilized probably because most labour work on the farm were done with little or no supervision and this must have contributed to its over utilization. Efficiency and productivity could be improved if the cotton farmers use more agrochemicals and less of fertilizer and labour.

Table 4: Estimated efficiency ratios using marginal utilization of input resources

\begin{tabular}{lcccc}
\hline Farm input resource & MVP & $\begin{array}{c}\text { MFC (unit } \\
\text { price) }\end{array}$ & MVP/MFC & $\begin{array}{c}\text { Resource } \\
\text { utilization }\end{array}$ \\
\hline 1. Fertilizer (kg) & 7.545 & 13.04 & 0.58 & Over utilized \\
2. Agrochemicals (litres) & 1628.745 & 692.71 & 2.35 & Under utilized \\
3. Labour (Man days) & 152.4 & 300 & 0.51 & Over utilized \\
\hline
\end{tabular}

Source: Field survey 2018

\section{Conclusion and Recommendations}

The study reveals that cotton production in the study area is dominated by small and marginal farmers within middle age group having small family size. The major determinants of cotton production were farm size, agrochemicals and labour with farm size having the highest contribution to cotton output. Major source of inefficiency in cotton production was educational status. The farmers were highly efficient in resource allocation although there is still room for improvement which will lead to higher yield and consequently more farm income without any additional cost. Marginal input of resource utilization reveals that all the inputs included in the stochastic frontier production model were not optimally used. Based on this finding, the following measures for improving cotton production are recommended:

I. Since literacy rate was found to be the major source of inefficiency in cotton production, intensive awareness campaign and regular extension visits by officials of ministry of agriculture, Maharashtra State should be provided to farmers in order to facilitate better use of recommended production packages;

II. Farmers are advised to form cooperative groups in order to facilitate easy access to key farm inputs such as agrochemicals for enhanced productivity. 


\section{References}

Coelli, O.J. (1995). Recent development in frontier estimation and efficiency measurement. Australian Journal of Agric. Economics, 39:219-245.

Geetha, R. S. and Mahesh, V. (2019). Minimum support prices (MSP) and its influence on cotton farming in India. Asian Journal of Agricultural Extension, Economics and Sociology, 30:1-8.

Kandidat, E. (2016). Cotton cultivation - An exploratory study of agricultural opportunities to fight poverty in India.

Khairo, S.A. and Battese, G.E. (2005). A study of technical inefficiencies of maize farmers within and outside the new agricultural extension program in the Harari region of Ethiopia. South African Journal of Agricultural Extension, 34:135-150.

Shelke, R.D., Katkade, J.L. and Jadhav, V.B. (2016). Resource productivity and resource use efficiency in Bt cotton production in Beed district. Agric. Update, 11: 129-132.

Manjunath, K., Swamy, P. S. D., Jamkhandi, B. R., and Nadoni, N. N. (2013). Resource use efficiency of bt cotton and non-bt cotton in haveri district of Karnataka.
International Journal of Agriculture and Food Science Technology, 4:253-258.

Muhammad A., Abdul, M., Tahir, M.A. and Fatima N. (2011). A resource use efficiency analysis of small Bt cotton farmers in Punjab, Pakistan. Pakistan Journal of Agricultural Sciences, 48: 75-81.

Mustapha, A., and Salihu A. (2015). Determinants of technical efficiency of maize/cowpea intercropping among women farmers in Gombe State, Nigeria. Journal of Agriculture and Sustainability 7(2): 245-258.

Ogunbile, A.O., Tabo, R. and Rahman S.A. (2002). Factors affecting adoption of ICSVIIII and ICSV 400 sorghum varieties in Guinea and Sudan Savannah of Nigeria. The plant scientist 3: 3235.

Tayade, P.M. and Borkar P. (2016). Resource use efficiency and returns to scale in small holder cotton farming system in Parbhani, Maharashtra. International Journal of Applied andPure Sciences and Agriculture, 2: 155-159.

USDA(2017). World cotton statistics. Retrieved from http://www.worldbank.org/data /reports. 